\title{
ODONATA OCCURRENCE IN CAVES: ACTIVE OR ACCIDENTALS? A NEW CASE STUDY
}

\author{
Raoul Manenti¹, Matteo Elio Siesa², and Gentile Francesco Ficetola ${ }^{1,3}$
}

\begin{abstract}
Caves are environments that host unique faunas and may be important for organisms not exclusively dependent on caves. The occurrence of epigean taxa in caves is often considered accidental, but their study can provide useful information on cave colonization. Records of Odonata underground are extremely scarce. We have identified larvae of Cordulegaster bidentata in two caves, one natural and one artificial, from Lombardy in northwestern Italy. They occurred in pools near the cave entrance that have 84 lux of maximum illuminance, reached in early spring. In both caves we found a high density of larvae, and some of them were at very advanced instars. They had an important role in the cave's trophic web, exerting a high predation pressure on larvae of the salamander Salamandra salamandra. The plasticity of some Odonata species may allow them to take advantage of underground springs.
\end{abstract}

\section{INTRODUCTION}

Caves are environments that host unique faunas. Cave communities include cave-dependent species, the so-called troglobites, with specific adaptations to subterranean environments (Pipan and Culver, 2012). Many species that are not cave-dependent, troglophiles, can also exploit subterranean environments during phases of their life cycles (Culver and Pipan, 2009). The study of typical epigean taxa that enter caves can be of great interest for understanding the mechanisms of cave colonization. Although in many cases epigean organisms that are more or less occasionally found in caves are considered accidentals and of limited interest for biospeleological studies, some authors emphasize that active exploitation of the cave environment is often mistaken for accidental occurrence (Romero, 2009).

Caves are generally stable environments with specific features, such as constant water availability and relatively constant temperatures that make them particularly suitable for certain species. For instance, in karstic landscapes, surface water is extremely limited, while water is more frequent underground. In these areas, underground water might be important for the reproduction of semi-aquatic insects. Several taxa of semi-aquatic insects have been observed in underground environments (reviewed in Romero, 2009). However, records of Odonata underground are extremely scarce, with most found in the grey literature. Thompson and Kiauta (1994) reviewed dragonfly observations from subterranean environments and reported 34 taxa from caves and other similar underground habitats, 17 of which are from Yucatan cenotes and constitute a peculiar habitat that is ecologically different from most caves. Most of the remaining records refer to individuals accidentally drifted into caves by floods or streams or that are listed without any additional information (Thompson and Kiauta, 1994). Records of Odonata from caves include Calopterix sp. larvae from the Lepini
Mountains in Italy (Latella, 1992) and adults of Hemicordulia australe at the entrance of a cave during winter in New Zealand (Marinov, 2010). Even if the occurrence may be accidental, the larvae of several species are able to survive, and in some cases, successfully metamorphose in caves (Thompson and Kiauta, 1994). There is also evidence of species that may actively select caves for breeding, as in the case of Gynacantha nourlangie in Australia (Thompson and Kiauta, 1994) and Somatochlora meridionalis in Italy (Carchini, 1992). Adults of $G$. nourlangie are often associated with caves, while the latter has been reported for two caves in Italy where its ability to breed in underground habitats could be an advantage because surface waters often dry up (Thompson and Kiauta, 1994). Nevertheless, ecological information on Odonata in caves remains extremely limited, both spatially and taxonomically.

In this study, we performed an extensive survey of the benthic communities in 52 natural and artificial spring caves in northern Italy to assess Odonata occurrence. Here we report the first two findings of Cordulegaster bidentata larvae in Italian underground springs, highlighting their role in the trophic web of these sites.

\section{Material AND Methods}

We surveyed natural and artificial caves in a karstic area between the Lecco and Como districts (Lombardy, northwestern Italy). See Manenti et al. (2009), Manenti et al. (2011), and Manenti and Ficetola (2013) for additional details on the study area. We chose to survey spring caves only, thus excluding caves entered by surface streams in which Odonata larvae could have passively drifted. We

\footnotetext{
${ }^{1}$ Dipartimento di Bioscienze, Università degli Studi di Milano, Via Celoria, 2620133 Milano (Italy),raoul.manenti@unimi.it

${ }^{2}$ Via L. Settembrini, 1420092 Cinisello Balsamo, Milano (Italy)

${ }^{3}$ Dipartimento di Scienze dell'Ambiente e del Territorio, Università di Milano Bicocca. Piazza della Scienza 1, 20126 Milano (Italy)
} 


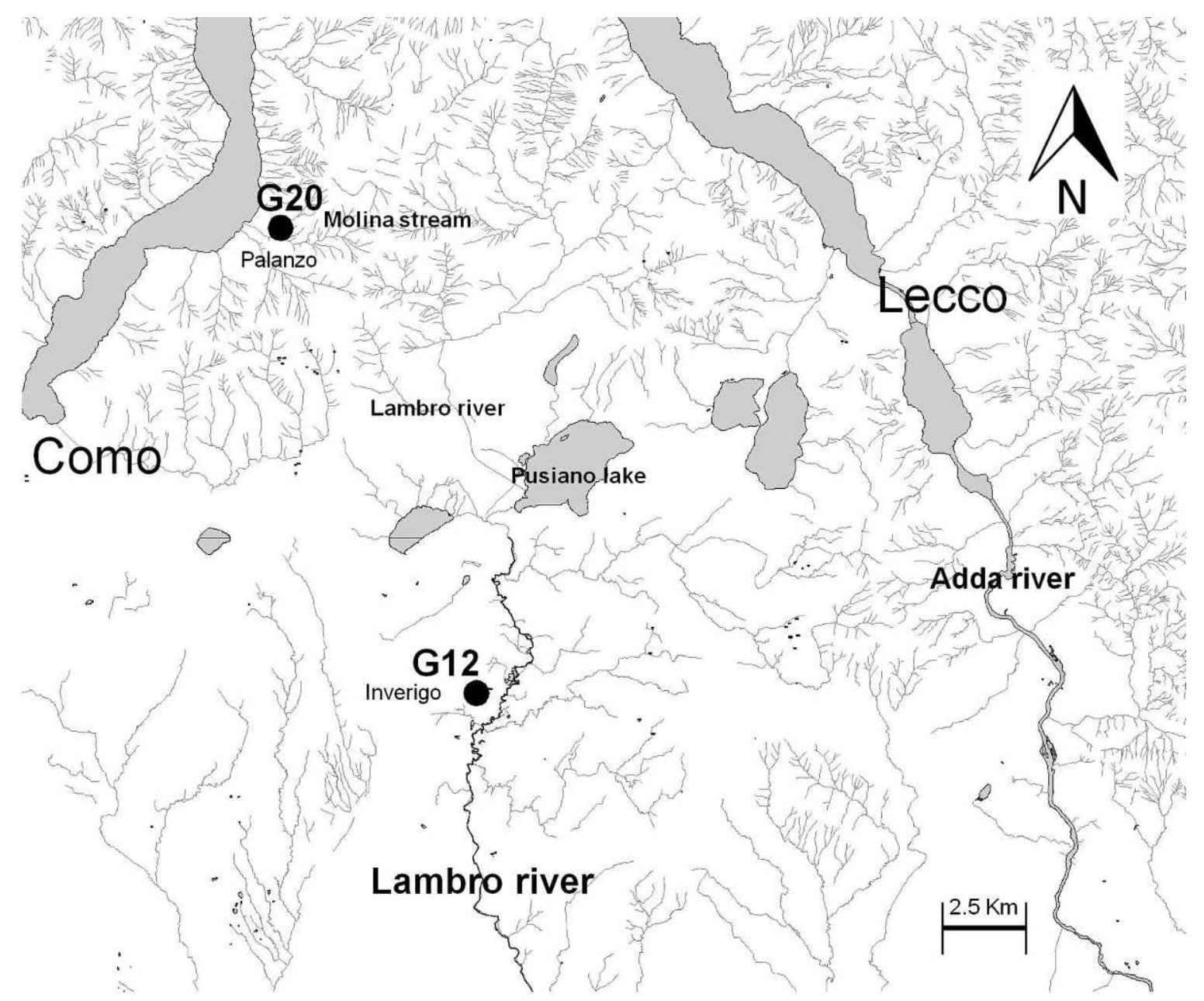

Figure 1. Study area and location (black circles) of the two caves with Cordulegaster bidentata larvae.

performed surveys between February 2009 and September 2012 in 26 natural and 26 artificial caves with underground water. The caves monitored constitute $80 \%$ of the natural spring caves and $100 \%$ of the known artificial underground springs in the study area. Each cave was monitored from 2 to 15 times (average: 4.1 surveys per cave). In at least 50\% of the surveys we recorded three parameters describing micro-climate and the physical environment: water temperature $\left({ }^{\circ} \mathrm{C}\right)$ and the maximum and minimum intensity of light incident on the water bodies, measured in lux. These parameters were measured using an EM882 multi-function thermo-hygrometer and a light meter (PCE Instruments). The minimum illuminance recordable by the light-meter was 0.01 lux. We used a fine-mesh net to collect the aquatic macroinvertebrates. The underground water bodies generally had limited surface area (average: $2.30 \mathrm{~m}^{2}$, maximum: $16 \mathrm{~m}^{2}$ ), and we were able to sample all their floors. For each larva of Cordulegaster bidentata found, we measured total length, head width (i.e., the maximum distance between the margins of the eyes) and, if present, wing sheaths' length. The latter characters allowed us to identify the final $(\mathrm{F}-0)$ or penultimate $(\mathrm{F}-1)$ instars as reported in
Ferreras-Romero and Corbet (1999) for C. boltoni. Several study caves were also breeding sites for the fire salamander Salamandra salamandra, which can be a frequent prey of Cordulegaster in pre-alpine streams (RM pers. obs.). As a measure of predation pressure, we counted the percentage of salamander larvae showing injuries suggesting predation attempts, and we used an unequal-variance $t$ test to compare the frequency of injured larvae between caves with and without $C$. bidentata.

\section{RESUlts}

We detected Cordulegaster bidentata in 2 caves out of the 52 sampled (Fig. 1). Water flows from both caves, and downstream of the caves there are no stable surface water bodies or streams because the water meets highly permeable sediments. Thus accidental occurrence of the larvae is unlikely.

The first cave is an artificial underground spring with a length of $5.3 \mathrm{~m}$. Its distance from the nearest other water is $41 \mathrm{~m}$. This cave (G12 in Fig. 1 and Table 1) was sampled monthly from September 2010 to February 2011 without 
Table 1. Main features of the two caves inhabited by $C$. bidentata.

\begin{tabular}{|c|c|c|c|c|c|c|c|c|c|}
\hline \multirow[b]{2}{*}{ Cave } & \multirow[b]{2}{*}{ Town } & \multirow[b]{2}{*}{ Locality } & \multirow{2}{*}{$\begin{array}{c}\text { Altitude, } \\
\text { amsl }\end{array}$} & \multicolumn{2}{|c|}{ Iluminance, lux } & \multirow{2}{*}{$\begin{array}{l}\text { Area, } \\
\mathrm{m}^{2}\end{array}$} & \multirow{2}{*}{$\begin{array}{l}\text { Depth, } \\
\text { cm }\end{array}$} & \multirow{2}{*}{$\begin{array}{c}\text { Other Taxa } \\
\text { Present }\end{array}$} & \multirow[b]{2}{*}{ Coordinates } \\
\hline & & & & $\max$ & $\min$ & & & & \\
\hline G20 & Faggeto Lario & Palanzo & 530 & 84 & 3.5 & 2.5 & 25 & $\begin{array}{l}\text { Lumbricidae } \\
\text { Chironomidae } \\
\text { Lymnephilidae }\end{array}$ & $\begin{array}{r}45^{\circ} 44^{\prime} 30^{\prime \prime} \mathrm{N} \\
9^{\circ} 14^{\prime} 7^{\prime \prime} \mathrm{E}\end{array}$ \\
\hline G12 & Inverigo & Orrido4 & 376 & 47 & 0.01 & 2.8 & 75 & $\begin{array}{l}\text { Tipulidae } \\
\text { Limonidae } \\
\text { Chironomidae } \\
\text { Lymnephilidae } \\
\text { Gordiidae }\end{array}$ & $\begin{array}{r}45^{\circ} 44^{\prime} 30^{\prime \prime} \mathrm{N} \\
3^{\circ} 17^{\prime} 21^{\prime \prime} \mathrm{E}\end{array}$ \\
\hline
\end{tabular}

detecting any dragonfly larva. Sampling was repeated in April and September 2012; in these sampling events we detected eight and five larvae of $C$. bidentata, respectively (maximum observed density: 2.8 larvae $/ \mathrm{m}^{2}$ ). The cave houses at its entrance a pool of $2.8 \mathrm{~m}^{2}$ with a maximum depth of $75 \mathrm{~cm}$. The maximum recorded illuminance was 47 lux in April, but during all the sampling events part of the pool was in complete darkness (illuminance 0.01 lux). Larvae were found at the bottom of the pool or along the edges. In April, we found four larvae at the F-1 stage, while in September, we found two larvae at the F-0 stage and two at F-1 stage.

The second cave was sampled in March 2010 without any observation of dragonfly larvae. In April 2012 we found seven larvae of $C$. bidentata. It is a natural cave with a length of $11 \mathrm{~m}$ and a large entrance (3.5-m wide). The cave (G20 in Fig. 1 and Table 1) contains a small stream with a pool $0.5 \mathrm{~m}$ from the entrance that has an area of $2.5 \mathrm{~m}^{2}$ and a maximum depth of $25 \mathrm{~cm}$. Its distance from the next stream is $28 \mathrm{~m}$. We recorded seven larvae inside the cave. Four larvae were at the F-0 stage and two at the F-1. Six larvae were found in the pool (larvae density $2.4 / \mathrm{m}^{2}$ ), while one was $3 \mathrm{~m}$ above in the small stream. The substrate is muddy and sandy and offers an ideal shelter for C. bidentata larvae. The maximum and minimum illuminance reached during the April sampling were 84 and 3.5 lux.

Both caves are breeding sites of the fire salamander Salamandra salamandra, which successfully grows and metamorphoses in caves (Manenti et al., 2011). In the caves with $C$. bidentata the average percentage of injured fire salamander larvae was $36 \%$, while it was $3.1 \%$ in the caves without $C$. bidentata. The frequency of injured tails was significantly higher in the caves with $C$. bidentata $(t=$ 6.03, $d f=2.57 p=0.014$ ) (Fig. 2).

\section{DisCusSion}

Cordulegaster bidentata is widespread in southern Europe (Carchini, 1983; Askew, 1988) and often occurs in the pre-alpine streams of Italy (Boano et al., 2007; Balestrazzi and Pavesi, 2008; Siesa, 2010), but to our knowledge, it has been reported in unusual habitats such as caves only once, in 1986 and 1987 from a cave in Switzerland (Thompson and Kiauta, 1994; Keim, 1996, p. 67-68). In that case, some exuviae and a dead female were reported in a subterranean lake.

Our survey provides new data for this species and presents interesting evidence for the ability of this species to actively use underground habitats. In particular, over 52 caves sampled, we found 2 sites, both with more than 2.5 $C$. bidentata larvae per square meter inside. The larvae of Cordulegaster bidentata usually develop in springs, small streams, or brooks with shallow water, low flow, and many pools (Heidemann and Seidenbusch, 2002). Both of our caves host underground springs with water bodies close to

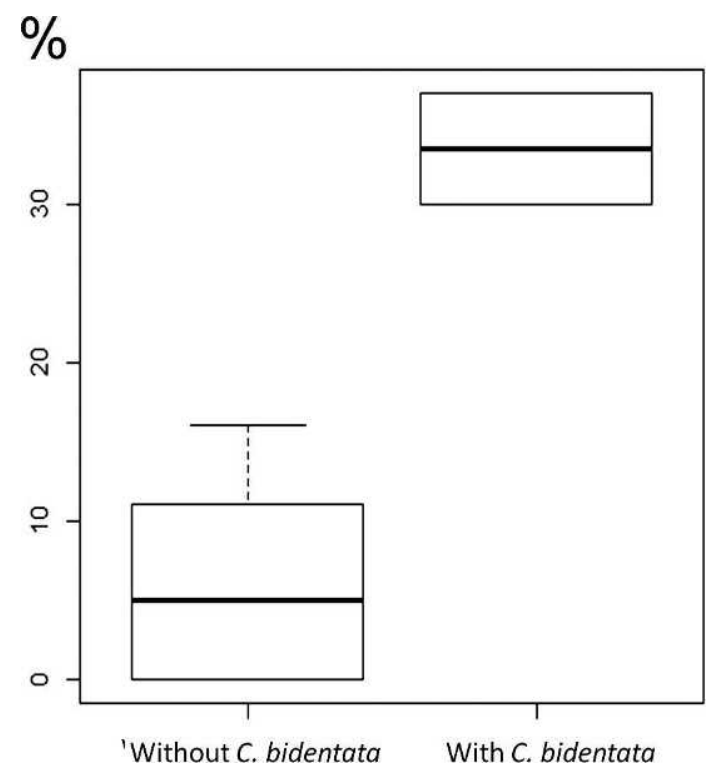

Figure 2. Boxplot of the percentage of fire salamander larvae with injured tails in caves without and with $C$. bidentata.

Journal of Cave and Karst Studies, December 2013•207 
the entrance. They are caves without influent streams, therefore, the presence of larvae cannot be explained by drifting or trapping from epigeous environments. Downstream from the entrance, the occurrence of highly permeable detritus does not allow the existence of permanent water nearby. The sites' conformations and distances from other streams or springs allow us to hypothesize two explanations for $C$. bidentata occurrence, both involving some form of active use of the cave. First, during periods of heavy rain, the springs may overflow, becoming connected with downstream watercourses. In these periods, dragonfly larvae could move upstream and reach sites not yet exploited to access trophic resources (Grand and Boudot, 2006). Second, the underground springs are not far from cave entrances, and the sectors closest to the entrance may receive some light. It is therefore possible that adults entering into caves may have laid eggs there. The observation of larvae at the final stage of development suggests that larvae can successfully grow in these underground pools, indicating an interesting plasticity of the species. The sites used are small cavities with suitable pools near the entrance that receive some light from outside, but they receive much less light than the standard habitat of this species. For instance, in April, with cloud cover at 12:00 pm the average minimum illuminance of surface streams inhabited by Cordulegaster within woodlands in our study area is 800 lux.

The use of caves by $C$. bidentata is infrequent, as we found them in only two caves and only during some surveys. Larvae are probably confined to illuminated water bodies near to the cave entrance. Underground springs usually have limited richness of invertebrates (Manenti et al., 2009), especially when compared to a typical stream inhabited by $C$. bidentata larvae (Lang et al., 2001). The scarcity of food items, the cold temperature, and the lack of light can be disadvantageous to the developmental rate of the larvae. On the other hand, the larval life cycle of $C$. bidentata can be longer than two years (Ferreras-Romero and Corbet, 1999; Grand and Boudot, 2006). In karstic areas, surface streams are often temporary, and underground springs can provide more stable environments. Furthermore, caves with $C$. bidentata contained salamander larvae that may constitute major prey items for dragonfly larvae.

Actually, larvae of $C$. bidentata can have an important role in the food webs of these underground environments. Larvae of the Cordulegaster genus are opportunistic predators that are able to consume a wide range of prey items, and they are often the dominant predators in the benthic communities of small streams and brooks (Bo et al., 2011); in pre-alpine streams, they often prey on fire salamander larvae. Salamander larvae are rather frequent in underground springs because these environments typically are without predators, which enhances larval survival (Manenti et al. 2011). If dragonfly larvae can reach these environments, they may find prey abundant, and their role as top predators can have an important function in the food web of caves.

\section{Conclusions}

Records of dragonflies underground are scarce (Thompson and Kiauta, 1994), especially concerning non-accidental cases and reproduction. The latter seems to be favored in the cases of crepuscular species or in areas where stable surface water is lacking (Carchini, 1992; Thompson and Kiauta, 1994). Our findings of Cordulegaster bidentata larvae could be linked to the latter aspect, especially considering the dry springs and summers that have been recorded in our study areas during the last two years. These results provide a new interesting case study for Odonata. Underground environments are among the lessknown habitats, but are an important compound of biodiversity.

\section{AcKNowledgements}

We are grateful to A. Binda and G. Morani for logistic support and assistance. We thank Prof. B. Kiauta, Prof. G. Carchini, Prof. D. J. Thompson and Dr. C. Keim for providing useful papers on odonates in caves. The comments of two anonymous reviewers improved a previous version of the manuscript.

\section{REFERENCES}

Askew, R.R., 1988, The Dragonflies of Europe: Colchester, Harley Books, $308 \mathrm{p}$.

Balestrazzi, E., and Pavesi, M., 2008, Gli Odonati della Lombardia. Consorzio Parco Monte Barro. Galbiate (LC), Quaderni della Biodiversità, CD-ROM.

Bo, T., Fenoglio, S., López-Rodriguez, M.J., and Tierno de Figueroa, J.M., 2011, Trophic behaviour of the dragonfly Cordulegaster boltoni (Insecta: Odonata) in small creeks in NW Italy: Entomologica Fennica, v. 22, p. 255-261.

Boano, G., Sindaco, R., Riservato, E., Fasano, S., and Barbero, R., 2007, Atlante degli Odonati del Piemonte e della Valle d'Aosta: Associazione Naturalistica Piemontese, Memorie VI, 160 p.

Carchini, G., 1983, Odonati (Odonata): Rome, Consiglio Nazionale delle Ricerche, $80 \mathrm{p}$.

Carchini, G., 1992, Some new records of odonate larvae in Italian caves, with a note on the advantage of cave-dwelling for Somatochlora meridionalis Nielsen (Odonata: Corduliidae): Opuscula Zoologica Fluminensia, v. 82, p. 15-21.

Culver, D.C., and Pipan, T., 2009, The Biology of Caves and Other Subterranean Habitats: New York, Oxford University Press, $254 \mathrm{p}$.

Ferreras-Romero, M., and Corbet, P.S., 1999, The life cycle of Cordulegaster boltonii (Donovan, 1807) (Odonata : Cordulegastridae) in the Sierra Morena Mountains (southern Spain): Hydrobiologia, v. 405, p. 39-48. doi:10.1023/A:1003763819991.

Grand, D., and Boudot, J.P., 2006, Les Libellules de France, Belgique et Luxembourg: Mèze, Biotope, 480 p.

Heidemann, H., and Seidenbusch, R., 2002, Larves et Exuvies des Libellules de France et d'Allemagne (Sauf de Corse): Bois-d'Arcy, Société française d'odonatologie, $416 \mathrm{p}$.

Keim, C., 1996, Libellules (Odonata) s du Valais (Suisse): Sion, La Murithienne.

Lang, C., Muller, H., and Waringer, J.A., 2001, Larval habitats and longitudinal distribution patterns of Cordulegaster heros Theischinger 
and $C$. bidentata Selys in an Austrian forest stream (Anisoptera : Cordulegastridae): Odonatologica, v. 30, p. 395-409.

Latella, L., 1992, La fauna cavernicola dei Monti Lepini: Rome, Notiziario del Circolo Speleologico Romano, v. 6/7, p. 77-118.

Manenti, R., and Ficetola, G.F., 2013, Salamanders breeding in subterranean habitats: local adaptations or behavioural plasticity?: Journal of Zoology, v. 289, p. 182-188. doi:10.1111/j.1469-7998.2012.00976.x.

Manenti, R., Ficetola, G.F., Bianchi, B., and De Bernardi, F., 2009, Habitat features and distribution of Salamandra salamandra in underground springs: Acta Herpetologica, v. 4, p. 143-151.

Manenti, R., Ficetola, G.F., Marieni, A., and De Bernardi, F., 2011, Caves as breeding sites for Salamandra salamandra: habitat selection, larval development and conservation issues: North-Western Journal of Zoology, v. 7, p. 304-309.
Marinov, M., 2010, Further knowledge of the colonisation of the South Island, New Zealand by Hemicordulia australiae (Odonata: Corduliidae): The Weta, v. 39, p. 17-28.

Pipan, T., and Culver, D.C., 2012, Convergence and divergence in the subterranean realm: a reassessment: Biological Journal of the Linnean Society, v. 107, p. 1-14. doi:10.1111/j.1095-8312.2012.01964.x.

Romero, A., 2009, Cave Biology: Life in Darkness: New York, Cambridge University Press, $291 \mathrm{p}$.

Siesa, M.E., 2010, Freshwater communities and biological invasions: Odonata, Amphibia and Procambarus clarkii: Ph.D. thesis, Milan, Università degli studi di Milano, $145 \mathrm{p}$.

Thompson, D.J., and Kiauta, B., 1994, Odonatospeleology: dragonflies in caves, with a checklist of the known records: Opuscula Zoologica Fluminensia, v. 118, p. 1-10. 